\title{
The relative influence of probabilities and payoffs upon perceived risk of a gamble '
}

\author{
PAUL SLOVIC \\ OREGON RESEARCH INSTITUTE, EUGENE
}

\begin{abstract}
Thirty-two college students rated the "risk" inherent in playing each of 27 gambles. The results indicated that perceived risk was determined primarily by a gamble's probability' of losing. The variance of a gamble had little influence upon its riskiness. The results were contrasted with those of a previous experiment in which $S$ s rated the attractiveness, rather than the riskiness, of these same bets.
\end{abstract}

Studies of decision making have expended a great deal of effort in an attempt to discover the manner in which probabilities and payoffs combine to determine the attractiveness of a risk. Concepts such as subjective probability and utility (Edwards, 1954), probability and variance preferences (Coombs \& Pruitt, 1960), and beliefs about the relative importance of probabilities and payoffs (Slovic \& Lichtenstein, 1967) have emerged from these studies as notions suitable for explaining and predicting risk-taking decisions.

While we are often interested in evaluating the worth or attractiveness of a risk in everyday life, we also are interested, in many cases, in describing the magnitude of risk or danger involved in an act. Riskiness is a meaningful concept, quite distinct from attractiveness, yet it has received little attention from the experimental psychologist.

It is generally conceded that uncertainty combined with the prospect of loss or failure lends a risky character to decision situations (Kogan \& Wallach, 1967, p. 113). All other things being equal, increasing the probability of losing or the amount which could be lost should increase the perceived risk. Yet, intuition suggests that probabilities and payoffs will not contribute equally to the perceived magnitude of a risk just as they do not make equal contributions to the attractiveness of a risk.

Another hypothesis, implicit in many studies of gambling decisions, is that the risk involved in a gamble is correlated positively with the variance or dispersion of possible payoffs (Allais, 1953; Coombs \& Pruitt, 1960; Slovic, 1962; Van der Meer, 1963; Kogan \& Wallach, 1967).

Slovic \& Lichtenstein (1967) described a technique in which systematic variation of probability of winning $\left(P_{W}\right)$, probability of losing $\left(P_{L}\right)$, amount to win $\left({ }_{W}\right)$, and amount to lose $\left(\$_{L}\right)$ across a set of gambles permitted the assessment of the independent contribution of each of these basic risk dimensions to the attractiveness of a gamble. The present study employs this same procedure in an attempt to discover the relative importance of these dimensions and variance in determining perceived risk.

Method

A special type of gamble was constructed which enabled probabilities of winning and losing as well as their respective payoffs to be varied independently. This type of stimulus, called a duplex gamble, is illustrated in Fig. 1. A duplex gamble is represented by two large discs, each with a pointer on it. The left-hand disc is used for determining winnings. The right-hand disc determines losses. To play, a person has to spin the pointers on both the winning and losing discs. This means that the player can win and not lose, lose and not win, both win and lose, or neither win nor lose. The expected value of a duplex gamble equals $\mathbf{P}_{W} \cdot \$_{W}+\mathbf{P}_{\mathbf{L}} \cdot \$_{\mathrm{L}} \cdot$ Its variance equals $\mathbf{P}_{\mathbf{W}}\left(1-\mathbf{P}_{\mathrm{W}}\right) \$_{\mathbf{W}}^{2}$ $+\mathrm{P}_{L}\left(1-\mathrm{P}_{\mathrm{L}}\right) \$ 2$. It can be argued that this type of gamble is as faithful an abstraction of real life decision situations as its more commonly studied counterpart in which $P_{L}=1-P_{W}$. For example, the choice of a particular job might offer some probability $\left(P_{W}\right)$ of a promotion and some probability $\left(P_{L}\right)$ of a transfer to an undesirable location, and it is possible that one of these events, both of them, or neither of them will occur.

The stimuli for this study were 27 duplex gambles. For these bets, $\mathrm{P}_{W}$ and $\mathrm{P}_{\mathrm{L}}$ each occurred three times at each of three levels, .2, .4, and .8; $\$ \mathrm{~W}$ and $\$_{\mathrm{L}}$ also occurred three times at each of three levels, $\$ 1, \$ 2$, and $\$ 4$. The four risk dimensions had zero intercorrelation across bets. The variances of these bets ranged between .4 and 6.4 .

The Ss were 32 undergraduates. They were asked to rate the degree of risk involved in playing each bet
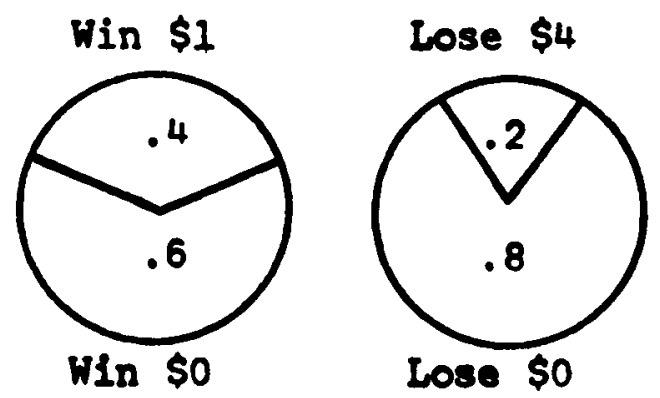

Fig. 1. Example of a duplex bet where $P_{W}=.4, \varsigma_{W}=\$ 1, P_{L}=.2$, and $\$_{L}=-\$ 4$. 
Table 1 Average correlations between risk dimensions and ratings of risk and attractiveness

\begin{tabular}{lcccc}
\hline Type of Rating & \multicolumn{4}{c}{ Risk Dimensions } \\
& $\mathrm{P}_{\mathrm{W}}$ & $\$_{\mathrm{W}}$ & $\mathrm{P}_{\mathrm{L}}$ & $\$_{\mathrm{L}}$ \\
Risk & -.45 & -.28 & .52 & .34 \\
Attractiveness* & .48 & .36 & -.39 & -.40 \\
\hline
\end{tabular}

*Data from 88 Ss in a study by Slovic \& Lichtenstein (1967).

on a 10-point scale where 0 stood for "virtually no risk," 4 and 5 represented "moderate risk," and 9 meant "extremely great risk." The Ss did not actually play any of the gambles. They were paid for their participation.

\section{Results}

The data analysis consisted of correlating each S'S ratings with the levels of each risk dimension across the 27 gambles. Since the risk dimensions were themselves uncorrelated, the absolute values of the correlations between risk dimensions and ratings are analogous to weights in a linear regression equation characteristic of each judge. The magnitude of these correlations provides information about the relative importance of each dimension in determining perceived riskiness.

The average correlations between risk dimensions and ratings of riskiness are presented at the top of Table 1. The bottom half of the table presents, for comparison, the average correlations obtained in a previous study by Slovic \& Lichtenstein (1967) in which $88 \mathrm{Ss}$ rated the attractiveness of playing these same 27 gambles. The results indicated that $P_{L}$ was the most important single determiner of perceived risk; $\$_{L}$ was far less important. Perspective with regard to the generality of this effect is given by the fact that the risk ratings of $24 \mathrm{Ss}$ correlated more highly with $P_{L}$ than with $\$_{L}$, while only five Ss had ratings that correlated more highly with $\$_{L}$. These data contrast with the ratings of attractiveness which were determined primarily by $\mathrm{P}_{W}$. A multivariate analysis of variance (Vanderplas, 1960) showed the differences between the mean vectors of absolute correlations generated by risk and attractiveness ratings to be significant at $p<.001$. A linear combination of the four risk dimensions, each weighted according to its correlation with the responses, predicted each S's ratings, whether of riskiness or attractiveness, quite well. This was indicated by average multiple correlations of .86 with either type of judgment.
Table 2 Percentage of persons for whom a given risk dimension was most important

\begin{tabular}{|c|c|c|c|c|}
\hline \multirow[t]{2}{*}{ Type of Rating } & \multicolumn{4}{|c|}{ Risk Dimensions } \\
\hline & $P_{W}$ & $\$ W$ & $\mathbf{P}_{\mathbf{L}}$ & $\$_{L}$ \\
\hline Risk & 27 & 04 & 57 & 12 \\
\hline Attractiveness* & 50 & 09 & 15 & 26 \\
\hline
\end{tabular}

*Data from 88 Ss in a study by Slovic \& Lichtenstein (1967).

The generality, across Ss, of the differences between the determinants of risk and attractiveness is further illustrated in Table 2, which presents the percentage of persons in each rating group for whom a given risk dimension was most important (correlated most highly with the responses).

Each person's ratings of risk also were correlated with the variance of each of the 27 duplex gambles. The highest of these correlations was .30. Only three others surpassed .20. The mean and median values across the 32 Ss were only .08. Correlations between perceived risk and range of payoffs were no higher. It appears that dispersion of payoffs is by no means as strong a determiner of risk as many have assumed.

\section{References}

ALLAIS, M. Le comportment de l'homme rationnel devant le risque. Critique des postulate et axioms de l'ecole americaine. Econometrica, 1953, 21, 503-546.

COOMBS, C. H., \& PRUITT, D. G. Components of risk in decision making: Probability and variance preferences. J. exp. Psychol., 1960, 60, 265-277.

EDWARDS, W. The theory of decision making. Psychol. Bull., 1954, $51,380-417$.

KOGAN, N., \& WALLACH, M. A. Risk taking as a function of the situation, the person, and the group. In G. Mandler (Ed.), New Directions in Psychology III. New York: Holt, Rinehart and Winston, 1967. Pp. 111-278.

SLOVIC, P. Convergent validation of risk taking measures. J. abnorm. Psychol, 1962, 65, 68-71.

SLOVIC, P., \& LICHTENSTEIN, S. C. The relative importance of probabilities and payoffs in risk taking. Oregon Res. Inst. res. Bull., $1967,7,7$.

VAN der MEER, H. C. Decision making: The influence of probability preference, variance preference, and expected value on strategy in gambling. Acta psychol., Amsterdam, 1963, 21, 231-259.

VANDERPLAS, J. M. Some tests of significance of multivariate data. J. gen. Psychol., 1960, 62, 257-268.

\section{Note}

1. This research was supported by Grant MH-04439 from the United States Public Health Service. Computing assistance was obtained from the Health Sciences Computing Facility, U.C.L.A., sponsored by NIH Grant FR-3. 